\title{
Changes in Physical Activity Following a Genetic-Based Internet-Delivered Personalized Intervention: Randomized Controlled Trial (Food4Me)
}

Cyril FM Marsaux ${ }^{1 *}, \mathrm{MSc}$; Carlos Celis-Morales ${ }^{2 *}, \mathrm{PhD}$; Katherine M Livingstone ${ }^{2}, \mathrm{PhD}$; Rosalind Fallaize ${ }^{3}, \mathrm{PhD}$; Silvia Kolossa ${ }^{4}$, MSc; Jacqueline Hallmann ${ }^{4}, \mathrm{MSc}$; Rodrigo San-Cristobal ${ }^{5}$, MSc; Santiago Navas-Carretero ${ }^{5,6}, \mathrm{PhD}$; Clare B O'Donovan ${ }^{7}$, MSc; Clara Woolhead ${ }^{7}$, MSc; Hannah Forster ${ }^{7}$, BSc (Hons); George Moschonis ${ }^{8}$, PhD; Christina-Paulina Lambrinou ${ }^{8}$, MSc; Agnieszka Surwillo ${ }^{9}$, MSc; Magdalena Godlewska ${ }^{9}$, MSc; Jettie Hoonhout ${ }^{10}$, $\mathrm{PhD}$; Annelies Goris ${ }^{11}$, PhD; Anna L Macready ${ }^{3}, \mathrm{PhD}$; Marianne C Walsh ${ }^{7}, \mathrm{PhD}$; Eileen R Gibney ${ }^{7}, \mathrm{PhD}$; Lorraine Brennan $^{7}, \mathrm{PhD}$; Yannis Manios ${ }^{8}, \mathrm{PhD}$; Iwona Traczyk ${ }^{9}, \mathrm{PhD}$; Christian A Drevon ${ }^{12}$, MD, PhD; Julie A Lovegrove ${ }^{3}$, PhD; J Alfredo Martinez ${ }^{5,6}$, PhD; Hannelore Daniel ${ }^{4}$, PhD; Michael J Gibney ${ }^{7}$, PhD; John C Mathers ${ }^{2}$, PhD; Wim HM Saris ${ }^{1}, \mathrm{MD}, \mathrm{PhD}$

\footnotetext{
${ }^{1}$ Department of Human Biology, NUTRIM School of Nutrition and Translational Research in Metabolism, Maastricht University Medical Centre + (MUMC+), Maastricht, Netherlands

${ }^{2}$ Human Nutrition Research Centre, Institute of Cellular Medicine, Newcastle University, Newcastle Upon Tyne, United Kingdom

${ }^{3}$ Hugh Sinclair Unit of Human Nutrition and Institute for Cardiovascular and Metabolic Research, University of Reading, Reading, United Kingdom

${ }^{4}$ Zentralinstitut für Ernährungs- und Lebensmittelforschung (ZIEL) Research Center of Nutrition and Food Sciences, Biochemistry Unit, Technische Universität München, München, Germany

${ }^{5}$ Department of Nutrition, Food Science and Physiology, Centre for Nutrition Research, University of Navarra, Pamplona, Spain

${ }^{6}$ Centro de Investigación Biomédica en Red-Fisiopatología de la Obesidad y Nutrición (CIBERobn), Instituto de Salud Carlos III, Madrid, Spain

${ }^{7}$ University College Dublin (UCD) Institute of Food and Health, University College Dublin, Belfield, Dublin, Ireland

${ }^{8}$ Department of Nutrition and Dietetics, Harokopio University, Athens, Greece

${ }^{9}$ National Food \& Nutrition Institute (IZZ), Warsaw, Poland

${ }^{10}$ Experiences Research Department, Philips Research, Eindhoven, Netherlands

${ }^{11}$ Personal Health Solutions, Philips Consumer Lifestyle, Amsterdam, Netherlands

${ }^{12}$ Department of Nutrition, Institute of Basic Medical Sciences, Faculty of Medicine, University of Oslo, Oslo, Norway

*these authors contributed equally
}

\section{Corresponding Author:}

Cyril FM Marsaux, MSc

Department of Human Biology

NUTRIM School of Nutrition and Translational Research in Metabolism

Maastricht University Medical Centre + (MUMC+)

PO Box 616

Maastricht, $6200 \mathrm{MD}$

Netherlands

Phone: 31433881379

Fax: 31433670976

Email: c.marsaux@maastrichtuniversity.nl

\section{Abstract}

Background: There is evidence that physical activity (PA) can attenuate the influence of the fat mass- and obesity-associated (FTO) genotype on the risk to develop obesity. However, whether providing personalized information on FTO genotype leads to changes in PA is unknown.

Objective: The purpose of this study was to determine if disclosing FTO risk had an impact on change in PA following a 6-month intervention. 
Methods: The single nucleotide polymorphism (SNP) rs9939609 in the FTO gene was genotyped in 1279 participants of the Food4Me study, a four-arm, Web-based randomized controlled trial (RCT) in 7 European countries on the effects of personalized advice on nutrition and PA. PA was measured objectively using a TracmorD accelerometer and was self-reported using the Baecke questionnaire at baseline and 6 months. Differences in baseline PA variables between risk (AA and AT genotypes) and nonrisk (TT genotype) carriers were tested using multiple linear regression. Impact of FTO risk disclosure on PA change at 6 months was assessed among participants with inadequate PA, by including an interaction term in the model: disclosure (yes/no) $\times$ FTO risk (yes/no).

Results: At baseline, data on PA were available for 874 and 405 participants with the risk and nonrisk FTO genotypes, respectively. There were no significant differences in objectively measured or self-reported baseline PA between risk and nonrisk carriers. A total of $807(72.05 \%)$ of the participants out of 1120 in the personalized groups were encouraged to increase PA at baseline. Knowledge of $F T O$ risk had no impact on PA in either risk or nonrisk carriers after the 6-month intervention. Attrition was higher in nonrisk participants for whom genotype was disclosed $(P=.01)$ compared with their at-risk counterparts.

Conclusions: No association between baseline PA and FTO risk genotype was observed. There was no added benefit of disclosing FTO risk on changes in PA in this personalized intervention. Further RCT studies are warranted to confirm whether disclosure of nonrisk genetic test results has adverse effects on engagement in behavior change.

Trial Registration: ClinicalTrials.gov NCT01530139; http://clinicaltrials.gov/show/NCT01530139 (Archived by WebCite at: http://www.webcitation.org/6XII1QwHz)

(J Med Internet Res 2016;18(2):e30) doi: 10.2196/jmir.5198

\section{KEYWORDS}

FTO; physical activity; personalized intervention; randomized controlled trial; genetic testing; disclosure; behavior change; Web based

\section{Introduction}

The prevalence of physical inactivity in Europe and worldwide is high [1]. Given that physical inactivity is among the top risk factors for noncommunicable diseases [2], finding effective ways to achieve long-lasting improvements in physical activity (PA) remains a major challenge [3]. While previous intervention strategies have mainly focused on a "one-size-fits-all" approach to change behavior, recent studies have used personalized approaches, such as tailored Web-based interventions [4,5]. There is inconsistent evidence on whether these personalized approaches are more effective at increasing PA than standard guidelines, and effects, when present, are often small and with short-term efficacy [6]. Concurrently, there has been a growing interest in using genetic information to personalize lifestyle interventions [7]. Although disclosure of such information does not appear to have unintended adverse effects, more randomized controlled trials (RCTs) are needed to establish whether gene-based personalized interventions promote greater behavior change than conventional "one-size-fits-all" interventions [8]. In particular, data on whether providing genetic information leads to an increase in PA are lacking.

The fat mass- and obesity-associated (FTO) gene has provided strong evidence of the genetic susceptibility to obesity. Polymorphisms in this gene located in intron 1 and exon 2 have been shown to be consistently and strongly associated with obesity-related markers [9,10]. For instance, individuals homozygous for the higher-risk allele, AA, of single nucleotide polymorphism (SNP) rs9939609 in the FTO gene FTO weighed, on average, $3 \mathrm{~kg}$ more and had 1.7-fold increased odds of having obesity compared with those homozygous for the lower-risk allele, TT [11]. Moreover, there is increasing evidence that the FTO genetic susceptibility to obesity can be modulated by lifestyle factors, and that PA, for example, may attenuate the effects of the FTO genotype on obesity-related traits [12-17]. However, to our knowledge there is no data on whether disclosing information on FTO genotype can motivate individuals to increase their PA. Elucidating whether genetic-based advice can promote improvements in PA behaviors may help in the design of more effective interventions, especially when tailored to individuals who would benefit most from increasing their PA.

As part of the Food4Me study (ClinicalTrials.gov number: NCT01530139) - a Web-based RCT in 7 European countries-we investigated the effects of 3 levels of personalized advice on changes in PA, including a level with genetic information on FTO [18,19]. See Multimedia Appendix 1 for the CONSORT-EHEALTH checklist [20]. We found that personalized feedback in general led to greater improvements in self-reported PA, but not in objectively measured PA, compared with standard guidelines [19]. However, we did not investigate the effect of disclosing genetic-based information on PA change, and whether the response differs between carriers of a genetic risk and nonrisk carriers. Thus, the aim of these analyses was to assess the impact of knowledge of FTO risk status on change in self-reported and objectively measured PA in Food4Me participants.

\section{Methods}

\section{Subjects}

Subjects were participants of the Food4Me study, a 6-month, Web-based RCT on personalized nutrition and lifestyle conducted in 7 European countries-Germany, Greece, Ireland, the Netherlands, Poland, Spain, and the United Kingdom. As outlined elsewhere [18], 1607 adults aged $\geq 18$ years were randomized to the study. Exclusion criteria included no or limited access to the Internet, following a prescribed diet, or 
having altered nutritional requirements because of a medical condition. The local ethics committee of each recruiting center approved the study protocol and all subjects provided informed consent digitally before participating.

\section{Study Design}

Participants were randomly allocated to one of the 4 groups-Level 0: standard, nonpersonalized, dietary and PA guidelines; Level 1: dietary and PA advice based on current diet and PA; Level 2: dietary and PA advice based on current diet, PA, and phenotype (eg, waist circumference and blood cholesterol); and Level 3: dietary and PA advice based on current diet, PA, phenotype, and genotype (eg, FTO). The randomization scheme has been described previously [18]. All data were collected remotely following standardized operating procedures. At baseline, participants received study kits by post containing all necessary materials, such as an accelerometer and DNA collection kit (see the Physical Activity Assessment and Genotyping sections below), to perform measurements at home, but used their own scales to measure body weight. Printed instructions were included and demonstration videos were available on the Food4Me website [18,21].

On the allocated study day and following an 8-hour overnight fast, participants collected a buccal cell sample for DNA; measured their height, weight, and waist circumference; and started wearing an accelerometer. The buccal cell sample was returned to the research center in a prepaid stamped addressed envelope and anthropometric measurement values were self-reported online. Questionnaires to be completed online the same day included the Baecke PA questionnaire (see the Physical Activity Assessment section below). Participants repeated the measurements, except DNA collection, at 3 and 6 months [18].

Following measurements at baseline and 3 months, participants received, at both time points, a personalized (Levels 1-3) or nonpersonalized (Level 0) report, including feedback on PA according to their group. The personalized feedback provided was based on a predefined set of algorithms, including anthropometric, PA (Levels 1-3), phenotypic (Levels 2 and 3), and genotypic (Level 3 only) data. Results in the personalized report were compared with recommendations for each anthropometric, PA (Levels 1-3), and phenotypic (Levels 2 and 3) item, using 3-color graded lines-green: good; amber: improvement recommended; and red: improvement strongly recommended. In addition, Level 3 participants received information in their report about 5 diet- and lifestyle-related genes [18]. For FTO, the message was "A specific variation of this gene is associated with a greater need to maintain a healthy body weight and engage in physical activity. A healthy weight combined with exercise may provide added health benefits for these individuals." Participants were informed whether they were carriers of the risk variant for the FTO SNP rs9939609 (yes or no, if they were genotyped AA or AT, or TT, respectively). Each personalized report (Levels 1-3) also contained a specific message related to body weight and PA. Additionally, for Level 3 participants this specific message referred to FTO. For example, for an AA/AT participant with increased body mass index (BMI), increased waist circumference, and low PA, the message was "We recommend reducing your body weight and waist circumference to a healthy normal range because you have a genetic variation that can benefit by reducing these 2 obesity markers. Also, your physical activity level is too low." Full details of the study design have been published elsewhere [18].

\section{Physical Activity Assessment}

\section{Objective Physical Activity}

PA was assessed objectively using the TracmorD triaxial accelerometer (Philips Consumer Lifestyle, the Netherlands) $[22,23]$. Participants were instructed to wear the accelerometer every day while awake, except when taking a shower, for the entire duration of the 6-month study. Participants uploaded data every 2 weeks onto the study server via the Internet. Data were recorded with a time-sampling interval of $1 \mathrm{~min}$. A day was considered valid if the participant had worn the TracmorD accelerometer between 10 and $18 \mathrm{~h}$. Wear time was defined as $24 \mathrm{~h}$ minus nonwear time. To define nonwear time, we adapted the recommendations of Choi et al [24] to the TracmorD accelerometer. R software version 3.1.2 (The R Foundation) [25] was used for PA data processing.

Daily PA level (PAL) - the ratio of total energy expenditure to basal metabolic rate-was derived from activity counts [22]. Time spent in sedentary behavior-corresponding to $<1.5$ metabolic equivalents (METs) - and moderate- and vigorous-intensity $\mathrm{PA}-3$ to $<6$ METs and $\geq 6$ METs, respectively-were calculated based on the application of thresholds for activity energy expenditure (AEE) equivalent to the METs thresholds. Daily AEE was calculated as follows:

Daily AEE $=(0.9 \times$ daily PAL - 1$) \times$ BMR (1)

where the daily basal metabolic rate (BMR) is estimated using the Oxford equations developed by Henry, based on sex, age, and weight [26].

PA estimates were calculated over a 2-week period at baseline and 6 months. This 2-week assessment period occurred before any feedback was given for the corresponding time point. Sufficient PA data at each time point was defined as having at least 3 valid weekdays and 2 valid weekend days of accelerometer wear during the 2 -week period. For individuals with sufficient PA data, mean data per day were calculated based on all valid week and weekend days of the assessment period as follows:

Mean $=($ mean for weekdays $\times 5+$ mean for weekend days $\times$ 2) / 7 (2).

For sedentary time and time spent in moderate PA and vigorous PA, weekly estimates were calculated as follows:

Mean $=($ mean for weekdays $\times 5+$ mean for weekend days $\times$ 2) (3).

\section{Self-Reported Physical Activity}

At each time point, participants completed the Baecke questionnaire online [27] based on their PA during the last month. This short, extensively validated questionnaire [28-30] is composed of 3 sections-work, sport, and nonsport 
leisure-with indices ranging from 1 to 5 and a sum total (ie, total activity index) ranging from 3 to 15 . Scores were calculated at baseline and month 6 , according to the questionnaire protocol [27].

\section{Genotyping}

Participants collected a buccal cell sample at baseline, using Isohelix SK-1 DNA buccal swabs and Isohelix Dri-capsules (LGC Genomics, Hertfordshire, UK). Samples were returned to the recruiting centers and shipped to LGC Genomics, who extracted the DNA and used competitive allele-specific polymerase chain reaction (KASP) genotyping assays to provide biallelic scoring of SNP rs9939609 in the FTO gene.

\section{Statistical Analyses}

Data are presented as means (SD) for continuous variables and as percentages for categorical variables, unless otherwise stated. A chi-square test was used to test if the observed FTO genotype counts were in Hardy-Weinberg equilibrium [31]. To examine if there was an association between PA and FTO genotype, we used baseline data and robust multiple linear regression models, based on computation of SMDM estimates [32] to account for violation of the normality assumption. FTO genotype was operationalized as risk (AA and AT) and nonrisk (TT).

To study the impact of knowledge of FTO risk status on changes in PA, we used two approaches. In the first approach or primary analysis, we investigated whether personalized advice based on genetic information (ie, FTO risk) was more effective at increasing PA than personalized advice without genetic-based information in FTO risk and nonrisk carriers. In this analysis, we compared Level 3 participants who received personalized advice to increase PA, including disclosure of FTO risk, with participants who received personalized advice to increase PA without any genetic-based information (pooled Levels 1 and 2 ). As a secondary analysis, we assessed whether personalized advice based on genetic information (ie, FTO risk) was more effective at increasing PA than standard guidelines (ie, nonpersonalized advice) in FTO risk and nonrisk carriers. This analysis compared Level 3 participants with the control group-Level 0, nonpersonalized guidelines. In order to match the characteristics of both groups, participants in the control group were included only if they had insufficient baseline PA (ie, they would have been advised to increase their PA if they had not been in the control group). For both primary and secondary analyses, we used robust multiple regression models, including an interaction term between FTO risk (yes or no) and disclosure of genetic information (yes or no). If there was no significant interaction, we looked at the main effects after removing the interaction term from the model. Models were adjusted for age, sex, country, BMI, season, accelerometer wear time, and baseline PA variable as appropriate. Additional sensitivity analyses were run, stratifying by sex and by tertile of baseline PA variables. Attrition rates between groups were compared using Pearson's chi-square tests. R software version 3.1.2 (The R Foundation) [25] was used to perform all analyses and the significance level was set at $P<.05$.

\section{Results}

\section{Attrition Rate and Compliance}

A total of 1607 individuals were randomized into the study (see Figure 1) and 127 (7.90\%) of them dropped out before starting the trial; their characteristics will be reported elsewhere. Genotype and PA data were available for 1279 of the 1480 $(86.42 \%)$ starters, which were therefore included in the baseline analysis (see Figure 1). Although sufficient accelerometer data were defined as having a minimum of 3 valid weekdays and 2 valid weekend days of accelerometer wear, $77.56 \%$ (992/1279) of subjects had 10 or more valid days of accelerometer wear at baseline-mean 11.3 days (SD 2.4): 8.2 weekdays (SD 1.9) and 3.2 weekend days (SD 0.8).

Among the 1120 participants who received personalized advice (Levels 1-3), 807 (72.05\%) were advised to increase their PA following assessment of baseline PA. Similarly, in the control group (Level 0), 276 of 360 (76.7\%) participants would have been advised to increase their PA if the algorithms applied to Levels 1-3 had been applied to the control group (see Figure 1 ). For these participants with inadequate $P A$, attrition rate was similar between groups $(14-15 \%, P=.45)$ at month 6 (see Figure 1). In the group where FTO risk was disclosed (Level 3), participants with the nonrisk (TT) genotype were more likely to drop out of the intervention than the at-risk (AA/AT) participants—attrition rate $22 \%$ (TT) versus $12 \%$ (AA/AT); odds ratio (OR) $2.04,95 \%$ CI 0.96-4.29, $P=.04$. This was also the case when considering all participants in Level 3 (ie, not only those advised to increase their PA) - attrition rate $20 \%$ (TT) versus $11 \%$ (AA/AT); OR 2.17, 95\% CI 1.13-4.17, $P=.01$ (see Table 1). There were no significant differences in attrition rates after 6 months between risk and nonrisk carriers in any other groups.

Although only 157 out of 1083 (14.50\%) participants with inadequate PA had dropped out by month 6 , compliance with wearing the accelerometer decreased during the study. Thus, $46.45 \%(503 / 1083)$ of subjects had data on FTO genotype, objective PA, and self-reported PA for both baseline and month 6 , and were included in the analyses on change in PA (see Figure 1). Of these, $85.5 \%(430 / 503)$ and $68.0 \%$ (342/503) had 10 days of valid accelerometer wear at baseline and month 6 , respectively. Mean number of valid days of accelerometer wear for these participants was 11.9 days (SD 2.1) at baseline-8.6 weekdays (SD 1.7) and 3.3 weekend days (SD 0.7) — and 10.4 days (SD 3.0) at month 6-7.7 weekdays (SD 2.3) and 2.7 weekend days (SD 1.1). This was similar for all intervention groups (data not shown for Levels 0-3). 
Table 1. Attrition rates after 6 months by intervention level.

\begin{tabular}{|c|c|c|c|c|c|c|c|c|}
\hline \multirow[t]{3}{*}{ Group characteristics } & \multicolumn{2}{|c|}{ Standard guidelines } & \multicolumn{4}{|c|}{ Personalized, nongene-based advice } & \multirow{2}{*}{\multicolumn{2}{|c|}{$\begin{array}{l}\text { Personalized and gene-based } \\
\text { advice } \\
\text { Level } 3\end{array}$}} \\
\hline & \multicolumn{2}{|l|}{ Level 0} & \multicolumn{2}{|l|}{ Level 1} & \multicolumn{2}{|l|}{ Level 2} & & \\
\hline & $\mathrm{TT}^{\mathrm{a}}$ & $\mathrm{AA} / \mathrm{AT}^{\mathrm{a}}$ & $\mathrm{TT}$ & AA/AT & $\mathrm{TT}$ & AA/AT & $\mathrm{TT}$ & AA/AT \\
\hline Participants, $\mathrm{n}$ & 112 & 247 & 127 & 244 & 117 & 255 & 113 & 257 \\
\hline Dropouts, n (\%) & $13(11.6)$ & $34(13.8)$ & $19(15.0)$ & $40(16.4)$ & $11(9.4)$ & $38(14.9)$ & $23(20.4)^{b}$ & $27(10.5)^{\mathrm{b}}$ \\
\hline
\end{tabular}

${ }^{\mathrm{a}} \mathrm{TT}$ and AA/AT are the nonrisk and risk genotypes, respectively, for the fat mass- and obesity-associated (FTO) rs9939609.

${ }^{\mathrm{b}}$ Significant difference in attrition rate between $F T O$ TT and AA/AT genotypes for Level 3 participants $(P=.01)$.

Figure 1. Flowchart of study procedures. Participants in Level 0 (controls) received standard, nonpersonalized guidelines during the intervention, whereas participants in Levels 1-3 received personalized advice. PA: physical activity; FTO: fat mass- and obesity-associated gene.

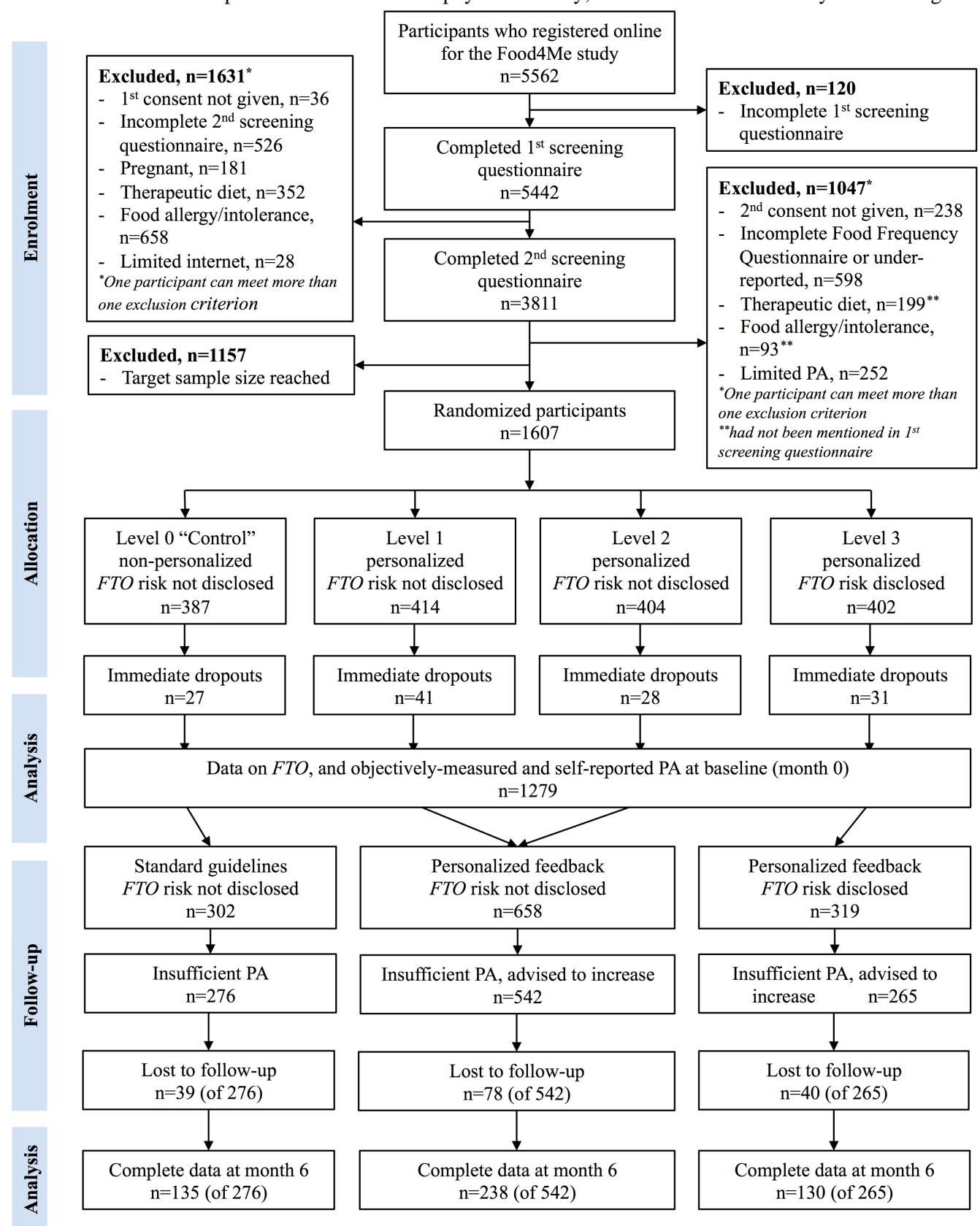

\section{Physical Activity and FTO Genotype}

The characteristics of the 1279 participants with baseline PA data both from accelerometers and self-reports, as well as data on FTO genotype, are presented in Table 2. Most participants were white, 743 (58.09\%) were women, and 588 (45.97\%) were overweight or obese. Genotype frequency for FTO rs 9939609 
did not deviate from Hardy-Weinberg equilibrium (TT=405, TA=641, and AA=233; $P=.48$ ).

Table 2. Characteristics of the participants included in baseline analysis.

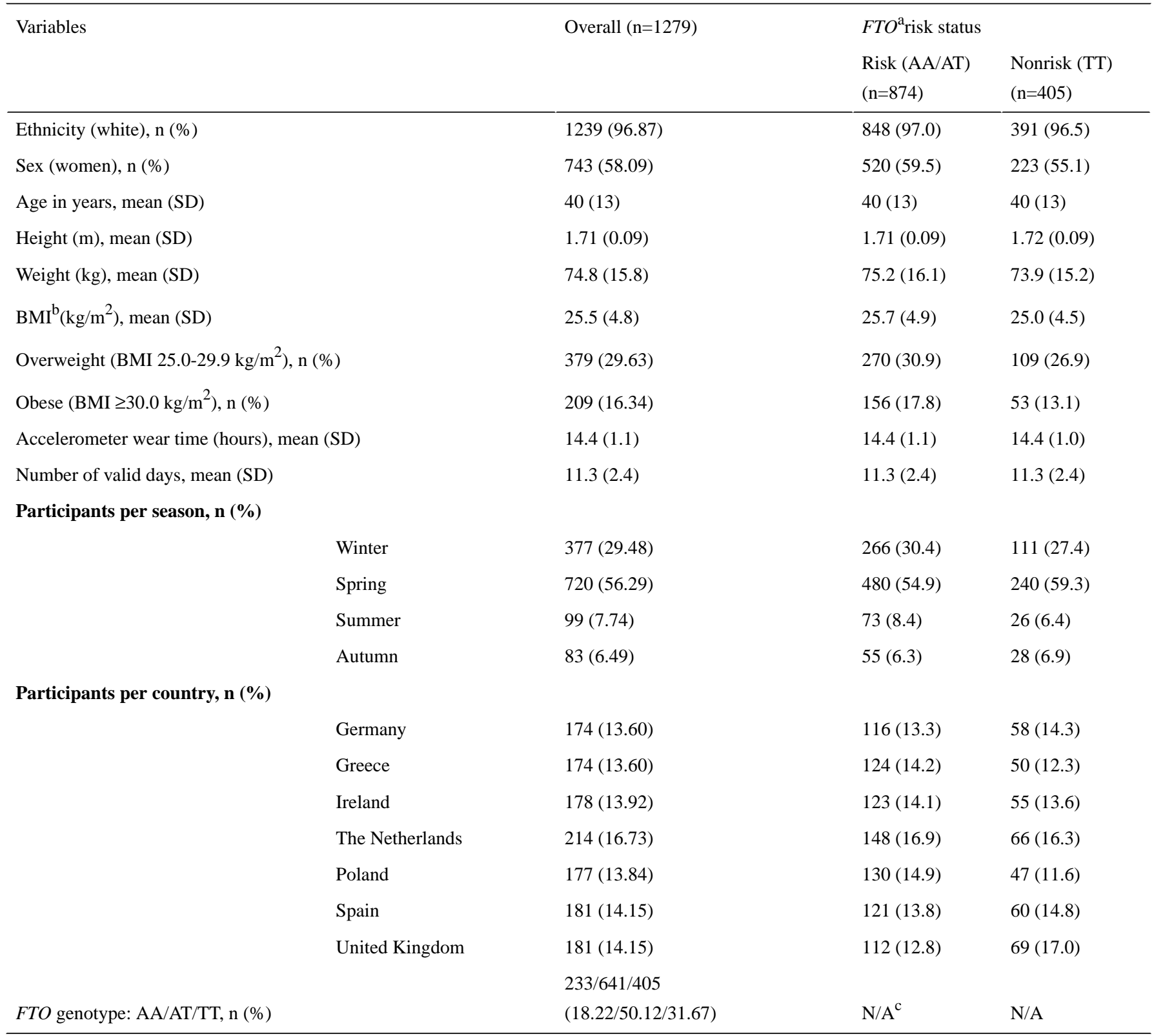

${ }^{\mathrm{a}}$ FTO: fat mass- and obesity-associated gene.

${ }^{\mathrm{b}} \mathrm{BMI}$ : body mass index.

${ }^{\mathrm{C}} \mathrm{N} / \mathrm{A}$ : not applicable.

We found no association between objectively measured PAL $(P=.35)$, moderate PA $(P=.28)$, vigorous PA $(P=.24)$, or sedentary time $(P=.71)$ at baseline and FTO risk status (see Figure 2, section a). Similarly, there was no significant difference in baseline self-reported PA between risk and nonrisk carriers $(P=.76)$ (see Figure 2, section $b)$.

\section{Primary Analysis: Effect of Disclosing FTO Genotype Status on Change in Physical Activity}

Table 3 displays the PA characteristics of genotyped participants advised to increase their PA at baseline, with objective PA and self-reported PA data at baseline and month 6 . 
Figure 2. Physical activity in FTO rs9939609 risk (AA/AT, n=874) and nonrisk (TT, n=405) carriers. FTO: fat mass- and obesity-associated gene. a. Objectively measured physical activity
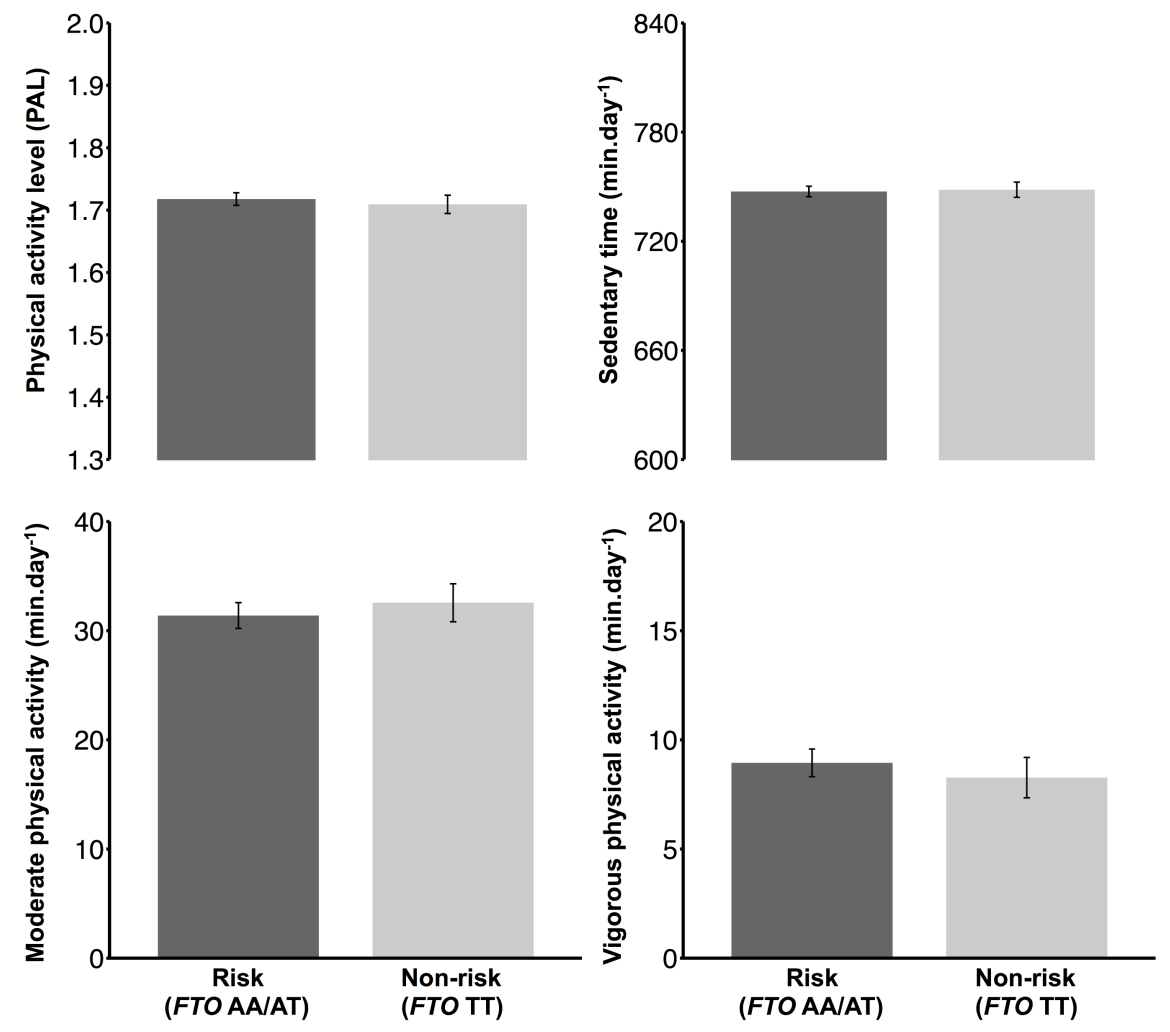

b. Self-reported physical activity

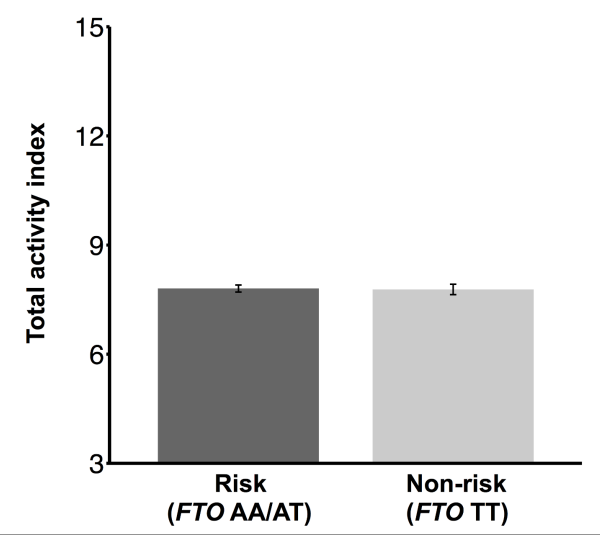


Table 3. Changes in physical activity (PA) from baseline to month 6 for participants receiving personalized advice to increase their PA.

\begin{tabular}{|c|c|c|c|c|}
\hline \multirow[t]{2}{*}{ Variables } & \multicolumn{2}{|c|}{ Disclosure (Level 3) } & \multicolumn{2}{|c|}{ Nondisclosure (Levels 1 and 2) } \\
\hline & $\begin{array}{l}F T O^{\mathrm{a}} \text { risk AA/AT } \\
(\mathrm{n}=91), \\
\text { mean }(\mathrm{SD})\end{array}$ & $\begin{array}{l}\text { FTO nonrisk TT } \\
(\mathrm{n}=39) \\
\text { mean }(\mathrm{SD})\end{array}$ & $\begin{array}{l}\text { FTO risk AA/AT } \\
(\mathrm{n}=160), \\
\text { mean }(\mathrm{SD})\end{array}$ & $\begin{array}{l}\text { FTO nonrisk TT } \\
(\mathrm{n}=78), \\
\text { mean }(\mathrm{SD})\end{array}$ \\
\hline \multicolumn{5}{|l|}{ Objective PA ${ }^{b}$} \\
\hline \multicolumn{5}{|l|}{ Daily PAL $^{c}$} \\
\hline Month 0 & $1.64(0.10)$ & $1.67(0.08)$ & $1.68(0.10)$ & $1.67(0.10)$ \\
\hline Month 6 & $1.66(0.14)$ & $1.70(0.13)$ & $1.70(0.14)$ & $1.70(0.17)$ \\
\hline \multicolumn{5}{|c|}{ Moderate PA (min/week) } \\
\hline Month 0 & $174(124)$ & $209(98)$ & $199(111)$ & $189(112)$ \\
\hline Month 6 & $206(146)$ & $249(120)$ & $218(145)$ & $221(130)$ \\
\hline \multicolumn{5}{|c|}{ Vigorous PA (min/week) } \\
\hline Month 0 & $37(54)$ & $48(67)$ & $54(73)$ & $49(64)$ \\
\hline Month 6 & $49(76)$ & $57(89)$ & $64(93)$ & $61(91)$ \\
\hline \multicolumn{5}{|c|}{ Sedentary time (min/week) } \\
\hline Month 0 & $5449(483)$ & $5391(479)$ & $5327(505)$ & $5433(485)$ \\
\hline Month 6 & $5271(606)$ & $5153(449)$ & $5172(541)$ & $5139(579)$ \\
\hline \multicolumn{5}{|c|}{ Self-reported PA: total activity index } \\
\hline Month 0 & $7.46(1.49)$ & $7.51(1.31)$ & $7.49(1.37)$ & $7.69(1.30)$ \\
\hline Month 6 & $8.00(1.37)$ & $7.89(0.99)$ & $7.84(1.29)$ & 7.99 (1.44) \\
\hline
\end{tabular}

${ }^{\mathrm{a}}$ FTO: fat mass- and obesity-associated gene.

${ }^{b}$ PA: physical activity.

${ }^{\mathrm{c}}$ PAL: physical activity level.

There was no significant interaction between disclosure of genetic information and FTO risk status on change in objectively measured or self-reported PA (all $P>.25$ ); this is illustrated in Figure 3. There was also no effect of knowledge of FTO genotype on objectively measured or self-reported PA (all $P>$.10) (see Table 3 and Figure 3).

\section{Secondary Analysis: Personalized Feedback Including Disclosure of Genetic Information Compared With Standard Guidelines}

Comparisons between participants in the highest level of personalization (Level 3) who were advised to increase their PA, and control participants (Level 0) who would have been

advised to increase PA if they had been in a personalized group, are given in Multimedia Appendix 2. There were no significant interactions between intervention levels and FTO risk status on change in PA. Change in objectively measured PA did not differ significantly between Level 3 and Level 0 participants for both risk and nonrisk carriers. However, Level 3 participants, irrespective of FTO risk status, had greater changes in self-reported PA than Level 0 participants (see Multimedia Appendix 2).

\section{Sensitivity Analyses}

Results and conclusions were similar when carrying out the analyses in men and women separately or after stratifying analyses by tertile of baseline PA variables (data not shown). 
Figure 3. Effect of knowledge of FTO risk status on change in physical activity (PA) in risk (AA/AT) and nonrisk (TT) carriers. Nondisclosure FTO risk carriers, $\mathrm{n}=160$; nondisclosure FTO nonrisk carriers, $\mathrm{n}=78$; disclosure FTO risk carriers, $\mathrm{n}=91$; disclosure FTO nonrisk carriers, $\mathrm{n}=39$. FTO: fat mass- and obesity-associated gene.

a. Objectively measured physical activity
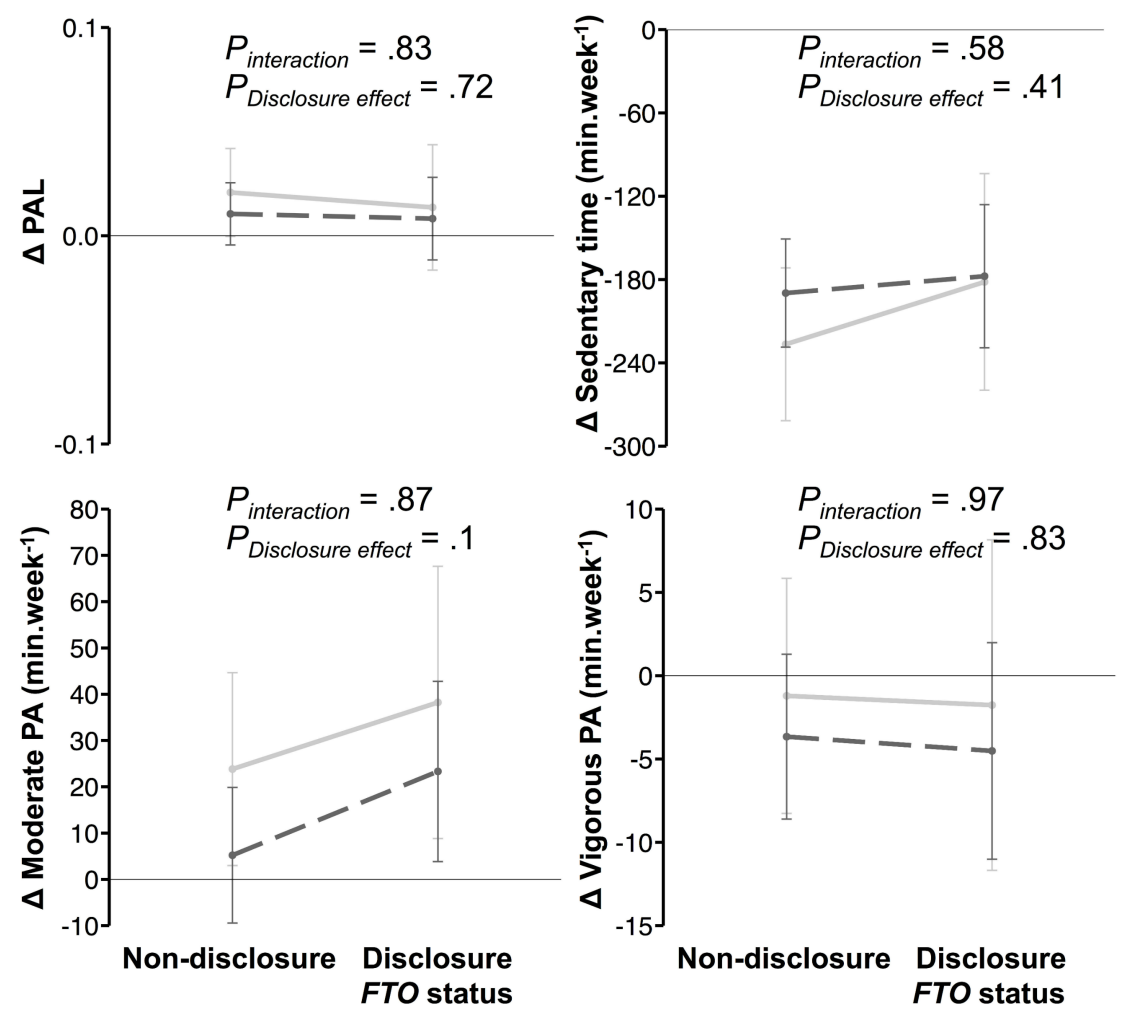

\section{b. Self-reported physical activity}

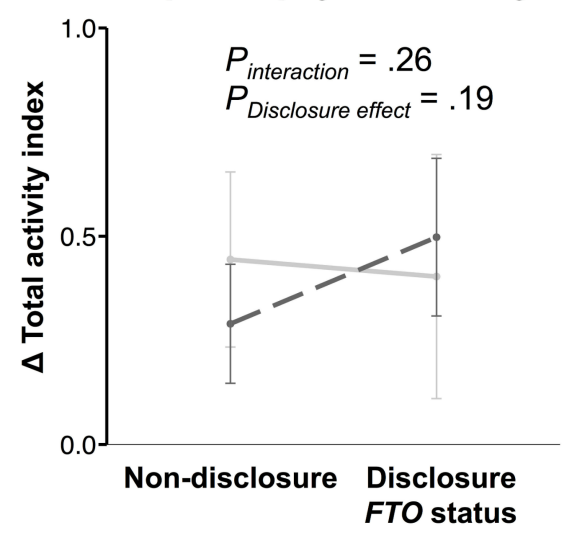

FTO risk carriers FTO non-risk carriers

\section{Discussion}

\section{Principal Findings}

Our main findings identified that there was no association between objectively measured or self-reported PA and FTO risk status. To our knowledge, our study is the first to investigate the impact of FTO genotype-based feedback on measured change in PA in the context of a personalized lifestyle intervention. We hypothesized that knowledge of carriage of FTO risk would lead to an increase in PA. However, we found no evidence that disclosing such information had any positive or negative effects on PA after a 6-month intervention.

\section{Comparison With Previous Work}

In the last decade, there has been a growing interest in personalizing lifestyle interventions using genetic tests. This has been done using DNA-based disease risk estimates, primarily in smokers or individuals at risk of certain conditions, such as Alzheimer's disease [8]. The hope was that providing such genetic information would motivate recipients to make beneficial behavioral changes beyond what could be achieved without such information. It is unclear whether knowledge of being predisposed to a greater genetic risk of disease would promote positive behavioral change and whether knowledge of only a small genetic risk (ie, a "lower" genetic risk) predisposition would lead to counterproductive behaviors under false reassurances [33]. In their 2010 review, Marteau et al reported no effect of adding DNA-based disease risk estimates 
compared with a non-DNA-based approach, in terms of smoking cessation, PA, or use of medication/vitamins. A beneficial effect of DNA-based risk estimates on dietary behavior was reported, although no benefit on intention to change dietary behavior was observed [8]. Since then, Hollands et al also observed no effect of communicating DNA-based risk assessments for Crohn's disease on smoking cessation, compared with standard risk assessment [34]. Grant et al reported that diabetes genetic risk counseling did not alter self-reported motivation or adherence to a prevention program in overweight individuals at risk for diabetes [35]. Although the design of our study was different because we did not aim to recruit individuals specifically at risk of a certain disease, our results are in line with the results of most studies performed so far. Recently, Meisel et al showed that young healthy individuals receiving FTO feedback in their weight control advice felt more prepared to control their weight than subjects receiving weight control advice only. However, this did not translate into behavioral change [36].

Evidence in favor of disclosing genetic information is thus limited. Even the favorable findings for dietary behavior change mentioned above in the review by Marteau et al are weak [8]. They are based on only 2 studies [37,38], which did not find significant effects when each study was evaluated individually. More recently, Nielsen et al concluded that disclosing genetic information for personalized nutrition resulted in greater improvements in intake of some dietary components compared with general population-based dietary advice. In reality, this was true only for sodium intake, but not for caffeine, vitamin $\mathrm{C}$, or added sugars, which were also studied. In addition, only individuals with the high-risk genotype status for the $A C E$ gene reduced their sodium intake more than controls based on self-reported food intake, not on objective biomarkers of intake [39]. Similarly, Hietaranta-Luoma et al reported that personal genetic information based on ApoE might have positive effects on triglyceride values and waist circumference, but this was observed only in the high-risk ع4+ individuals [40].

Data suggest that providing genetic test results indicating a higher genetic risk does not lead to fatalism [8]. Furthermore, there is no indication that disclosing only a small genetic risk or a lower-risk test result promotes counterproductive behaviors. Similarly, in our study we found no differences in change in PA between individuals aware of their nonrisk FTO status and individuals aware of a risk, or not aware of their genotype. However, we did observe that the attrition rate was significantly greater among individuals informed of their nonrisk FTO status as compared to the other groups. Given the amount and variety of information provided to participants during the Food4Me study, it seems unlikely that this genetic information would be responsible for the higher number of dropouts. Nonetheless, this should be studied further, as it may indicate that such individuals felt the intervention was less relevant for them. Grant et al also reported that subjects receiving lower-risk genetic results showed lower intent to do exercise compared with controls, although there were no differences in terms of attendance to the diabetes prevention program [35].

Personalized feedback led to greater improvements in self-reported PA, but not objectively measured PA, compared with standard guidelines, as reported previously [19]
Discrepancies between self-reported and objectively measured PA have been noted by others. For instance, Wanner et al, in a Web-based tailored PA intervention, reported some improvements in self-reported PA after 6 weeks and 13 months of follow-up, but no differences between individuals in tailored and control groups, and no improvement in objectively measured PA for any group [41]. However, in our study we did find greater improvements in self-reported PA in tailored groups as compared with the controls. It could be that participants desired to comply with recommendations and that receiving more personalized feedback (Levels 2 and 3) increased this desire further. Furthermore, here we show that the bigger improvements in self-reported PA reported earlier are irrespective of FTO genotype, and are not related to knowing one's risk status for FTO. Thus, it is unlikely that subjects with the high-risk variant would feel more pressured to report that they did better, compared with those with the low-risk variant. Finally, we did not observe an association between FTO risk and PA measured objectively or self-reported. This supports studies published thus far that have used mainly self-reported data $[15,42,43]$.

\section{Strengths and Limitations}

This study is the first to report the impact of disclosing information on FTO risk status on measured changes in PA. Our PA questionnaire has been validated against doubly labeled water and accelerometry $[27,30,44]$, and has been used in large European cohorts before [45,46]. However, self-reports introduce large measurement error [47] and the Baecke questionnaire is no exception [48]. Thus, a strength of this study was the objective assessment of PA using triaxial accelerometers. Although accelerometers underestimate certain activities, such as cycling, swimming, or resistance training, the TracmorD model used in this study has been validated against doubly labeled water [22] and it has been shown to be reliable and accurate [49-51].

By design, we recruited individuals interested in taking part in a personalized intervention on nutrition and lifestyle, which is less representative than a European-wide survey. Nonetheless, our participants were broadly representative of the European adult population, most of whom had adequate nutrient intakes but could benefit from improved dietary choices and greater PA [52]. Given that Food4Me was an intervention that targeted multiple dietary and lifestyle behaviors, the genetic results might have also been diluted by the amount of information provided. Moreover, the genetic feedback was a positive reinforcement. Participants with the higher-risk genotype would only benefit more by reducing their weight or increasing their PA. It is possible that the impact would have been greater if participants had been made more aware of the links between obesity and lifelong ill health. Furthermore, genetic feedback provided by health professionals skilled in genetic counseling might have been more effective that written feedback. However, this would have been more expensive and outside the scope of this study, which was designed to test the effects of an Internet-delivered intervention. Such interventions are thought to offer considerable advantages in terms of reach, scalability, and sustainability [53]. Attrition rates $(\sim 15 \%)$ were as expected and compliance with the measurements was good, except for wearing the monitor. 
Only half of the participants had accelerometer data for both baseline and month 6 -whereas $>75 \%$ had self-reported PA data at both time points-which limited the size of the sample analyzed in the PA analyses. It is possible that wearing the monitor for 6 months was too demanding for the amount of feedback given. It may be important for future studies that participants be able to visualize their activity levels, in real time, whenever desired (eg, on an accompanying website). Improvements in activity measurement may reduce participants' confusion and/or frustration. Having personalized coaches available, who can also operate online, may have motivated participants to wear their accelerometer and to improve their PA, although this also means extra costs. For the sole purpose of assessment, better compliance may be obtained by sending out monitors and collecting them back directly after assessment [54]. In spite of this, our sample size was acceptable, and the results did not change when looking at all self-reported PA data available.

\section{Conclusions}

There was no added benefit of knowledge of FTO risk on change in PA in this intervention study. Although there were no differences in outcome measures between participants informed of a nonrisk and those informed of a risk, or those not informed of their FTO risk status, the nonrisk subjects were more likely to drop out of the study by 6 months. More studies are needed to confirm whether disclosure of lower-risk genetic test results has adverse effects on engagement in behavioral changes. Before that, more effort should be devoted to identify the features necessary to engage individuals, how to frame the feedback, and how to coach effectively, especially those at risk, to reduce health inequalities.

\section{Acknowledgments}

This work was funded by the EU FP7 project Food4Me (KBBE.2010.2.3-02, Project no. 265494).

\section{Authors' Contributions}

JCM was the Food4Me intervention study coordinator. CFMM performed the statistical analysis for the manuscript. ERG, LB, YM, IT, CAD, JAL, JAM, WHMS, HD, MG, and JCM contributed to the research design. CFMM, CCM, RSC, SNC, COD, CW, HF, RF, ALM, SK, JHa, CPL, GM, AS, MG, MCW, and JCM conducted the intervention. CFMM, WHMS, CCM, AG, and JHo contributed to physical activity measurements. CFMM, CCM, KML, and WHMS drafted the paper. All authors contributed to a critical review of the manuscript during the writing process. All authors approved the final version to be published.

\section{Conflicts of Interest}

JH and AG are employed by Philips. The other authors have no competing interests.

\section{Multimedia Appendix 1 \\ CONSORT-EHEALTH checklist V1.6.1 [20]. \\ [PDF File (Adobe PDF File), 677KB-Multimedia Appendix 1]}

\section{Multimedia Appendix 2}

Changes from baseline in physical activity (PA) for participants who received the highest level of personalized advice (including genetic information, Level 3) and told to increase their PA, and for the controls who received standard guidelines (Level 0), but would have been advised to increase their PA if they had not been controls. Data are presented as mean (SD). FTO: fat massand obesity-associated gene.

\section{[PDF File (Adobe PDF File), 26KB-Multimedia Appendix 2]}

\section{References}

1. Hallal PC, Andersen LB, Bull FC, Guthold R, Haskell W, Ekelund U, Lancet Physical Activity Series Working Group. Global physical activity levels: Surveillance progress, pitfalls, and prospects. Lancet 2012 Jul 21;380(9838):247-257. [doi: 10.1016/S0140-6736(12)60646-1] [Medline: 22818937]

2. Noncommunicable Diseases Country Profiles 2011. Geneva, Switzerland: World Health Organization; Sep 2011.

3. Ekelund U, Ward HA, Norat T, Luan J, May AM, Weiderpass E, et al. Physical activity and all-cause mortality across levels of overall and abdominal adiposity in European men and women: The European Prospective Investigation into Cancer and Nutrition Study (EPIC). Am J Clin Nutr 2015 Mar;101(3):613-621 [FREE Full text] [doi: 10.3945/ajcn.114.100065] [Medline: 25733647]

4. Godino JG, Watkinson C, Corder K, Marteau TM, Sutton S, Sharp SJ, et al. Impact of personalised feedback about physical activity on change in objectively measured physical activity (the FAB study): A randomised controlled trial. PLoS One 2013;8(9):e75398 [FREE Full text] [doi: 10.1371/journal.pone.0075398] [Medline: 24066178] 
5. Hansen AW, Grønbæk M, Helge JW, Severin M, Curtis T, Tolstrup JS. Effect of a Web-based intervention to promote physical activity and improve health among physically inactive adults: A population-based randomized controlled trial. J Med Internet Res 2012;14(5):e145 [FREE Full text] [doi: 10.2196/jmir.2109] [Medline: 23111127]

6. Broekhuizen K, Kroeze W, van Poppel MN, Oenema A, Brug J. A systematic review of randomized controlled trials on the effectiveness of computer-tailored physical activity and dietary behavior promotion programs: An update. Ann Behav Med 2012 Oct;44(2):259-286 [FREE Full text] [doi: 10.1007/s12160-012-9384-3] [Medline: 22767052]

7. Collins F. Has the revolution arrived? Nature 2010 Apr 1;464(7289):674-675. [doi: 10.1038/464674a] [Medline: 20360716]

8. Marteau TM, French DP, Griffin SJ, Prevost AT, Sutton S, Watkinson C, et al. Effects of communicating DNA-based disease risk estimates on risk-reducing behaviours. Cochrane Database Syst Rev 2010(10):CD007275. [doi: 10.1002/14651858.CD007275.pub2] [Medline: 20927756]

9. Loos RJ, Bouchard C. FTO: The first gene contributing to common forms of human obesity. Obes Rev 2008 May;9(3):246-250. [doi: 10.1111/j.1467-789X.2008.00481.x] [Medline: 18373508]

10. Loos RJ, Yeo GS. The bigger picture of FTO: The first GWAS-identified obesity gene. Nat Rev Endocrinol 2014 Jan;10(1):51-61 [FREE Full text] [doi: 10.1038/nrendo.2013.227] [Medline: 24247219]

11. Frayling TM, Timpson NJ, Weedon MN, Zeggini E, Freathy RM, Lindgren CM, et al. A common variant in the FTO gene is associated with body mass index and predisposes to childhood and adult obesity. Science 2007 May 11;316(5826):889-894 [FREE Full text] [doi: 10.1126/science.1141634] [Medline: 17434869]

12. Andreasen CH, Stender-Petersen KL, Mogensen MS, Torekov SS, Wegner L, Andersen G, et al. Low physical activity accentuates the effect of the FTO rs9939609 polymorphism on body fat accumulation. Diabetes 2008 Jan;57(1):95-101 [FREE Full text] [doi: 10.2337/db07-0910] [Medline: 17942823]

13. Demerath EW, Lutsey PL, Monda KL, Linda Kao WH, Bressler J, Pankow JS, et al. Interaction of FTO and physical activity level on adiposity in African-American and European-American adults: The ARIC study. Obesity (Silver Spring) 2011 Sep;19(9):1866-1872 [FREE Full text] [doi: 10.1038/oby.2011.131] [Medline: 21593801]

14. Jonsson A, Renström F, Lyssenko V, Brito EC, Isomaa B, Berglund G, et al. Assessing the effect of interaction between an FTO variant (rs9939609) and physical activity on obesity in 15,925 Swedish and 2,511 Finnish adults. Diabetologia 2009 Jul;52(7):1334-1338. [doi: 10.1007/s00125-009-1355-2] [Medline: 19373445]

15. Kilpeläinen TO, Qi L, Brage S, Sharp SJ, Sonestedt E, Demerath E, et al. Physical activity attenuates the influence of FTO variants on obesity risk: A meta-analysis of 218,166 adults and 19,268 children. PLoS Med 2011 Nov;8(11):e1001116 [FREE Full text] [doi: 10.1371/journal.pmed.1001116] [Medline: 22069379]

16. Rampersaud E, Mitchell BD, Pollin TI, Fu M, Shen H, O'Connell JR, et al. Physical activity and the association of common FTO gene variants with body mass index and obesity. Arch Intern Med 2008 Sep 8;168(16):1791-1797 [FREE Full text] [doi: 10.1001/archinte.168.16.1791] [Medline: 18779467]

17. Vimaleswaran KS, Li S, Zhao JH, Luan J, Bingham SA, Khaw K, et al. Physical activity attenuates the body mass index-increasing influence of genetic variation in the FTO gene. Am J Clin Nutr 2009 Aug;90(2):425-428 [FREE Full text] [doi: 10.3945/ajcn.2009.27652] [Medline: 19553294]

18. Celis-Morales C, Livingstone KM, Marsaux CF, Forster H, O'Donovan CB, Woolhead C, et al. Design and baseline characteristics of the Food4Me study: A Web-based randomised controlled trial of personalised nutrition in seven European countries. Genes Nutr 2015 Jan;10(1):450 [FREE Full text] [doi: 10.1007/s12263-014-0450-2] [Medline: 25491748]

19. Marsaux CF, Celis-Morales C, Fallaize R, Macready AL, Kolossa S, Woolhead C, et al. Effects of a Web-based personalized intervention on physical activity in European adults: A randomized controlled trial. J Med Internet Res 2015;17(10):e231 [FREE Full text] [doi: 10.2196/jmir.4660] [Medline: 26467573]

20. Eysenbach G, CONSORT-EHEALTH Group. CONSORT-EHEALTH: Improving and standardizing evaluation reports of Web-based and mobile health interventions. J Med Internet Res 2011;13(4):e126 [FREE Full text] [doi: 10.2196/jmir.1923] [Medline: 22209829]

21. Food4Me. 2011. URL: http://www.food4me.org [accessed 2015-03-26] [WebCite Cache ID 6XJSSOSJD]

22. Bonomi AG, Plasqui G, Goris AH, Westerterp KR. Estimation of free-living energy expenditure using a novel activity monitor designed to minimize obtrusiveness. Obesity (Silver Spring) 2010 Sep;18(9):1845-1851. [doi: 10.1038/oby.2010.34] [Medline: 20186133]

23. Philips DirectLife. 2011. URL: http://www.directlife.philips.com [accessed 2015-03-26] [WebCite Cache ID 6XJUgQaGy]

24. Choi L, Liu Z, Matthews CE, Buchowski MS. Validation of accelerometer wear and nonwear time classification algorithm. Med Sci Sports Exerc 2011 Feb;43(2):357-364 [FREE Full text] [doi: 10.1249/MSS.0b013e3181ed61a3] [Medline: 20581716]

25. R Development Core Team. R: A Language and Environment for Statistical Computing. Vienna, Austria: R Foundation for Statistical Computing; 2014.

26. Henry CJ. Basal metabolic rate studies in humans: Measurement and development of new equations. Public Health Nutr 2005 Oct;8(7A):1133-1152. [Medline: 16277825$]$

27. Baecke JA, Burema J, Frijters JE. A short questionnaire for the measurement of habitual physical activity in epidemiological studies. Am J Clin Nutr 1982 Nov;36(5):936-942 [FREE Full text] [Medline: 7137077] 
28. Montoye HJ, Kemper HCG, Saris WHM. Measuring Physical Activity and Energy Expenditure. Champaign, IL: Human Kinetics; 1996.

29. Philippaerts RM, Lefevre J. Reliability and validity of three physical activity questionnaires in Flemish males. Am J Epidemiol 1998 May 15;147(10):982-990 [FREE Full text] [Medline: 9596477]

30. Philippaerts RM, Westerterp KR, Lefevre J. Doubly labelled water validation of three physical activity questionnaires. Int J Sports Med 1999 Jul;20(5):284-289. [doi: 10.1055/s-2007-971132] [Medline: 10452224]

31. Graffelman J. Graphical Tests for Hardy-Weinberg Equilibrium. Version 1.5.5. Vienna, Austria: R Foundation for Statistical Computing; 2015 Feb 24. URL: https://cran.r-project.org/web/packages/HardyWeinberg/HardyWeinberg.pdf]WebCite Cache ID 6ex6SqUYY]

32. Rousseeuw P, Croux C, Todorov V, Ruckstuhl A, Salibian-Barrera M, Verbeke T, et al. Basic Robust Statistics. Version 0.92-5. Vienna, Austria: R Foundation for Statistical Computing; 2015 Jul 22. URL: https://cran.r-project.org/web/packages/ robustbase/robustbase.pdf [accessed 2016-01-31] [WebCite Cache ID 6ex6jtMlB]

33. Evans JP, Meslin EM, Marteau TM, Caulfield T. Genomics. Deflating the genomic bubble. Science 2011 Feb 18;331(6019):861-862. [doi: 10.1126/science.1198039] [Medline: 21330519]

34. Hollands GJ, Whitwell SC, Parker RA, Prescott NJ, Forbes A, Sanderson J, et al. Effect of communicating DNA based risk assessments for Crohn's disease on smoking cessation: Randomised controlled trial. BMJ 2012;345:e4708 [FREE Full text] [Medline: 22822007]

35. Grant RW, O'Brien KE, Waxler JL, Vassy JL, Delahanty LM, Bissett LG, et al. Personalized genetic risk counseling to motivate diabetes prevention: A randomized trial. Diabetes Care 2013 Jan;36(1):13-19 [FREE Full text] [doi: 10.2337/dc12-0884] [Medline: 22933432]

36. Meisel SF, Beeken RJ, van Jaarsveld CH, Wardle J. Genetic susceptibility testing and readiness to control weight: Results from a randomized controlled trial. Obesity (Silver Spring) 2015 Feb;23(2):305-312 [FREE Full text] [doi: 10.1002/oby.20958] [Medline: 25522302]

37. Chao S, Roberts JS, Marteau TM, Silliman R, Cupples LA, Green RC. Health behavior changes after genetic risk assessment for Alzheimer disease: The REVEAL Study. Alzheimer Dis Assoc Disord 2008;22(1):94-97 [FREE Full text] [doi: 10.1097/WAD.0b013e31815a9dcc] [Medline: 18317253 ]

38. Marteau T, Senior V, Humphries SE, Bobrow M, Cranston T, Crook MA, Genetic Risk Assessment for FH Trial Study Group. Psychological impact of genetic testing for familial hypercholesterolemia within a previously aware population: A randomized controlled trial. Am J Med Genet A 2004 Jul 30;128A(3):285-293. [doi: 10.1002/ajmg.a.30102] [Medline: $\underline{15216550]}$

39. Nielsen DE, El-Sohemy A. Disclosure of genetic information and change in dietary intake: A randomized controlled trial. PLoS One 2014;9(11):e112665 [FREE Full text] [doi: 10.1371/journal.pone.0112665] [Medline: 25398084]

40. Hietaranta-Luoma H, Akerman K, Tahvonen R, Puolijoki H, Hopia A. Using individual, ApoE genotype-based dietary and physical activity advice to promote healthy lifestyles in Finland-Impacts on cardiovascular risk markers. Open J Prev Med 2015;5:206-217.

41. Wanner M, Martin-Diener E, Braun-Fahrländer C, Bauer G, Martin BW. Effectiveness of active-online, an individually tailored physical activity intervention, in a real-life setting: Randomized controlled trial. J Med Internet Res 2009;11(3):e23 [FREE Full text] [doi: 10.2196/jmir.1179] [Medline: 19666456]

42. Gustavsson J, Mehlig K, Leander K, Lissner L, Björck L, Rosengren A, et al. FTO genotype, physical activity, and coronary heart disease risk in Swedish men and women. Circ Cardiovasc Genet 2014 Apr;7(2):171-177 [FREE Full text] [doi: 10.1161/CIRCGENETICS.111.000007] [Medline: 24622111]

43. Harbron J, van der Merwe L, Zaahl MG, Kotze MJ, Senekal M. Fat mass and obesity-associated (FTO) gene polymorphisms are associated with physical activity, food intake, eating behaviors, psychological health, and modeled change in body mass index in overweight/obese Caucasian adults. Nutrients 2014 Aug;6(8):3130-3152 [FREE Full text] [doi: 10.3390/nu6083130] [Medline: 25102252]

44. Philippaerts RM, Westerterp KR, Lefevre J. Comparison of two questionnaires with a tri-axial accelerometer to assess physical activity patterns. Int J Sports Med 2001 Jan;22(1):34-39. [doi: 10.1055/s-2001-11359] [Medline: 11258639]

45. Tehard B, Saris WH, Astrup A, Martinez JA, Taylor MA, Barbe P, et al. Comparison of two physical activity questionnaires in obese subjects: The NUGENOB study. Med Sci Sports Exerc 2005 Sep;37(9):1535-1541. [Medline: 16177606]

46. Larsen TM, Dalskov S, van Baak M, Jebb S, Kafatos A, Pfeiffer A, et al. The Diet, Obesity and Genes (Diogenes) Dietary Study in eight European countries - A comprehensive design for long-term intervention. Obes Rev 2010 Jan;11(1):76-91 [FREE Full text] [doi: 10.1111/j.1467-789X.2009.00603.x] [Medline: 19470086]

47. Prince SA, Adamo KB, Hamel ME, Hardt J, Connor GS, Tremblay M. A comparison of direct versus self-report measures for assessing physical activity in adults: A systematic review. Int J Behav Nutr Phys Act 2008;5:56 [FREE Full text] [doi: 10.1186/1479-5868-5-56] [Medline: 18990237$]$

48. Walsh MC, Hunter GR, Sirikul B, Gower BA. Comparison of self-reported with objectively assessed energy expenditure in black and white women before and after weight loss. Am J Clin Nutr 2004 Jun;79(6):1013-1019 [FREE Full text] [Medline: 15159231] 
49. Dannecker KL, Sazonova NA, Melanson EL, Sazonov ES, Browning RC. A comparison of energy expenditure estimation of several physical activity monitors. Med Sci Sports Exerc 2013 Nov;45(11):2105-2112 [FREE Full text] [doi: 10.1249/MSS.0b013e318299d2eb] [Medline: 23669877]

50. Plasqui G, Bonomi AG, Westerterp KR. Daily physical activity assessment with accelerometers: New insights and validation studies. Obes Rev 2013 Jun;14(6):451-462. [doi: 10.1111/obr.12021] [Medline: 23398786]

51. Valenti G, Camps SG, Verhoef SP, Bonomi AG, Westerterp KR. Validating measures of free-living physical activity in overweight and obese subjects using an accelerometer. Int J Obes (Lond) 2014 Jul;38(7):1011-1014. [doi: 10.1038/ijo.2013.195] [Medline: 24166066]

52. Livingstone KM, Celis-Morales C, Navas-Carretero S, San-Cristobal R, O'Donovan CB, Forster H, et al. Profile of European adults interested in Internet-based personalised nutrition: The Food4Me study. Eur J Nutr 2015 Apr 17:1-11. [doi: 10.1007/s00394-015-0897-y] [Medline: 25893715]

53. Celis-Morales C, Lara J, Mathers JC. Personalising nutritional guidance for more effective behaviour change. Proc Nutr Soc 2015 May;74(2):130-138. [doi: 10.1017/S0029665114001633] [Medline: 25497396]

54. Troiano RP, McClain JJ, Brychta RJ, Chen KY. Evolution of accelerometer methods for physical activity research. Br J Sports Med 2014 Jul;48(13):1019-1023 [FREE Full text] [doi: 10.1136/bjsports-2014-093546] [Medline: 24782483]

\author{
Abbreviations \\ AEE: activity energy expenditure \\ BMI: body mass index \\ BMR: basal metabolic rate \\ CIBERobn: Centro de Investigación Biomédica en Red-Fisiopatología de la Obesidad y Nutrición \\ FTO: fat mass- and obesity-associated gene \\ IZZ: National Food \& Nutrition Institute \\ KASP: competitive allele-specific polymerase chain reaction \\ MET: metabolic equivalent \\ MUMC+: Maastricht University Medical Centre + \\ N/A: not applicable \\ NUTRIM: Nutrition and Translational Research in Metabolism \\ OR: odds ratio \\ PA: physical activity \\ PAL: physical activity level \\ RCT: randomized controlled trial \\ SNP: single nucleotide polymorphism \\ UCD: University College Dublin \\ ZIEL: Zentralinstitut für Ernährungs- und Lebensmittelforschung
}

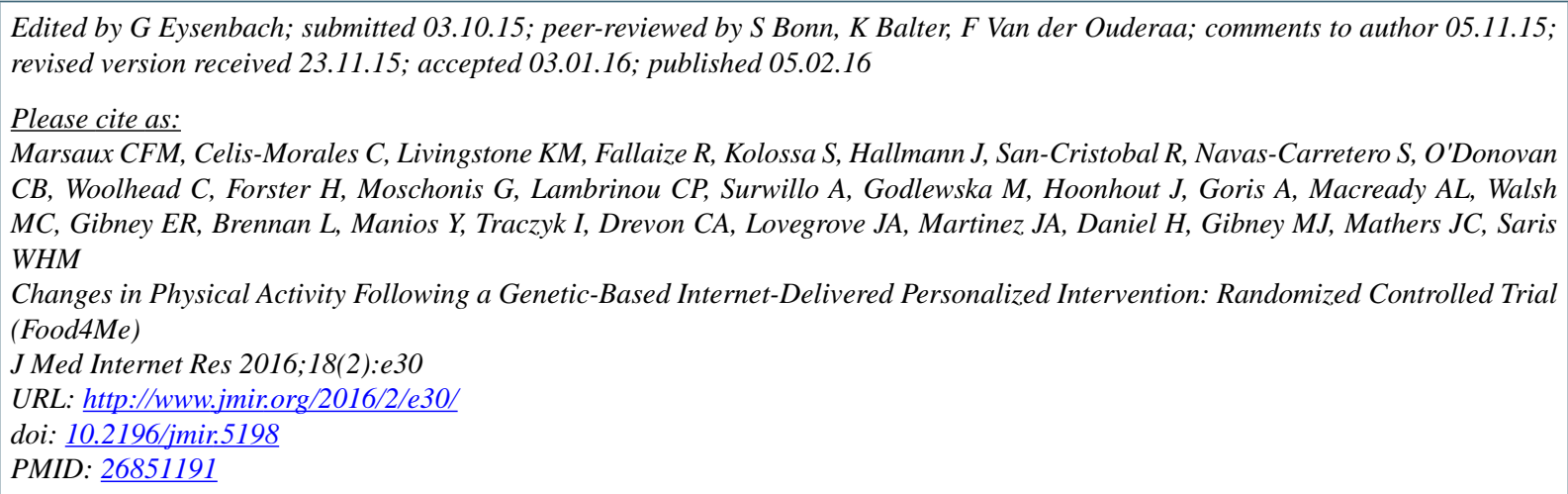

(C) Cyril FM Marsaux, Carlos Celis-Morales, Katherine M Livingstone, Rosalind Fallaize, Silvia Kolossa, Jacqueline Hallmann, Rodrigo San-Cristobal, Santiago Navas-Carretero, Clare B O'Donovan, Clara Woolhead, Hannah Forster, George Moschonis, Christina-Paulina Lambrinou, Agnieszka Surwillo, Magdalena Godlewska, Jettie Hoonhout, Annelies Goris, Anna L Macready, Marianne C Walsh, Eileen R Gibney, Lorraine Brennan, Yannis Manios, Iwona Traczyk, Christian A Drevon, Julie A Lovegrove, J Alfredo Martinez, Hannelore Daniel, Michael J Gibney, John C Mathers, Wim HM Saris. Originally published in the Journal of Medical Internet Research (http://www.jmir.org), 05.02.2016. This is an open-access article distributed under the terms of the 
Creative Commons Attribution License (http://creativecommons.org/licenses/by/2.0/), which permits unrestricted use, distribution, and reproduction in any medium, provided the original work, first published in the Journal of Medical Internet Research, is properly cited. The complete bibliographic information, a link to the original publication on http://www.jmir.org/, as well as this copyright and license information must be included. 